Food and family practices: teenagers, eating and domestic life in differing socioeconomic circumstances

*Corresponding author

Professor Kathryn Backett-Milburn

Public Health Sciences

School of Clinical Sciences and Community Health

College of Medicine and Veterinary Medicine

The University of Edinburgh

Medical School

Teviot Place

Edinburgh EH8 9AG

Email: k.milburn@ed.ac.uk

Tel:01316506196

Dr Wendy Wills

CRIPACC

University of Hertfordshire

College Lane Campus

Hatfield AL10 9AB

Email: w.j.wills@ herts.ac.uk

Tel: 01707286161

Dr Mei-Li Roberts

BACYS Degree Course Leader/Research Fellow

UHI Centre for Rural Childhood

Perth College UHI

Crieff Road

Perth PH1 2NX

Email:Mei-Li.Roberts@perth.uhi.ac.uk

Tel: 01738877279

Dr Julia Lawton

Public Health Sciences

School of Clinical Sciences and Community Health

College of Medicine and Veterinary Medicine

The University of Edinburgh

Medical School

Teviot Place

Edinburgh EH8 9AG

Email: J.Lawton@ed.ac.uk

Tel:01316506197 


\title{
Food and family practices: teenagers, eating and domestic life in differing socio- economic circumstances
}

\begin{abstract}
This paper draws on accounts from young teenagers and their parents in two linked qualitative studies of families living in Scotland in differing socio-economic circumstances. We compare and contrast teenager experiences of eating practices and food choice in these families. We show the range of meanings attached to how, where and what these teenagers and their parents described as everyday eating behaviours at home and locate these in the wider constraints, opportunities and aspirations affecting their lives.
\end{abstract}

\section{Key words}

eating practices; families; teenagers; domestic life; qualitative; social class 


\section{Food and family practices: teenagers, eating and domestic life in differing socio- economic circumstances}

\section{Introduction}

'Family' is created through a myriad of mundane everyday practices (Morgan 1996) of which domestic provision of food remains a central element. However, although families are accepted as the primary setting for the establishment of patterns of food choice and consumption in childhood (Dietz 2001), how parents and family background actually affect what teenagers eat at home on a daily basis is less clear. Not only is the collective identity of 'family' being created through everyday food choices and eating behaviours in the home but so also are the individual identities of family members (Devault 1991, Lupton 1994, Valentine 1999, Wright-St Clair et al. 2005).

In this paper we draw on two linked qualitative studies carried out in Scotland with young teenagers and their parents living in contrasting socio-economic circumstances. In study one we sampled those living in more disadvantaged socio-economic circumstances, more 'working class' (w/c) families, and in study two those living in higher SES, more 'middle class' (m/c) families. Here we examine the accounts of food and family practices of young teenagers in their homes and the negotiations between parents and teenagers surrounding these processes (Dixey et al 2001, Kaufman and Karpati 2007). We relate these to the wider constraints, opportunities and aspirations affecting families' lives (Backett-Milburn et al. 2006, Devine et al 2006). 
An important focus of our work was on the question 'does class matter?'. In this paper we draw on already published data from study one (w/c) and new analyses, some of which is under consideration for publication, from study two $(\mathrm{m} / \mathrm{c})$. Through making comparisons between these two sets of findings, this paper highlights issues of class based dispositions and practices. We first show how the differing domestic environments and expectations of parents in each study may be seen as the background for the teenagers' own accounts. We then explore the teenagers' own perspectives on tastes, preferences and parental control.

\section{Background}

Food and eating related practices in the home are both embedded in and reflective of people's everyday family and domestic lives and socio-cultural circumstances; they are dynamic and culturally responsive (Crossley 2004, Warin et al 2008). Family routines and identities are created and reinforced through the preparation of food for other family members (Mintz and DuBois 2002, Caplan 1997). Individuals become connected when they eat together (Wright-St Clair 2005) although the sharing of food in families with young teenagers can highlight tensions and conflict during this phase of the life course when young people seek to become more autonomous.

Young people's diets have come increasingly under the spotlight as considerable attention has been paid to the so-called 'obesogenic environment' (Egger and Swinburn 1997), focussing particularly on the dietary, commercial, lifestyle and social contexts 
which appear to foster less healthy eating practices (Colls and Evans 2008).

Consequently, there is more information about the characteristics and contexts of population groups who seem particularly affected by health damaging circumstances and environments, and weight increasing behaviours, than about other, usually more affluent, groups who seem somewhat less affected by these trends (Ball and Crawford 2005). It is valuable also to understand the social and cultural conditions which might be seen as promoting more positive dietary health and physical well-being in the face of trends which seem to be challenging these aspects of teenagers' lives (Sarlia-Lahteenkorva 2007).

Here we take social class as being a hierarchical (and unequal) framework of relationships which arise from the social organisation of labour, education, wealth and income (Bradley 1996). It is widely accepted that the unequal material circumstances associated with class distinctions influence peoples' lives and health (Williams 1995) and there has been a reignition of interest in class studies in geography (Dowling 2009). Through examination of the everyday lived experience of deprivation or affluence we can see how class might underpin growing inequalities in health. Bourdieu (1984), in his work on habitus, argued that social distinctions are maintained through the production and control of bodily practices, which are often mundane and taken-for-granted (Williams 1995). This implies that daily practices and beliefs surrounding diet, health and weight might provide a 'structuring structure' which, whilst serving to distinguish one class group from another, would be 'neither known nor chosen by [such groups]' (Williams 2003: 143). A lack of qualitative research specifically focussing on families, 
class and eating practices means that the mechanisms which might explain differences and similarities between different groups remain largely unexplored.

However, in the related field of health relevant behaviour, Bourdieu and others suggested that lower social class groups may have a more utilitarian attitude towards health, valuing bodies free from illness and capable of performing everyday activities (Bourdieu 1984, d'Houtard and Field 1984). The middle-classes, however, may be more likely to value enhanced wellbeing, rather than merely a functional absence of disease (Blaxter 1990, d'Houtard and Field, 1984). Quantitative explorations of the role of class in explaining young peoples' health-relevant behaviours suggests that structurally determined experiences may not be as influential as in previous generations (West and Sweeting 2004). Such issues are, however, likely to be complex and dynamic. Some evidence, for example, suggests that young people from working class backgrounds start following potentially problematic health trajectories earlier than their middle class peers whilst other work indicates that, as young teenagers start to move away from family influence, this may perhaps result in a 'blending'of peer groups from differing socio-economic circumstances (West and Sweeting 2004).

It is important to understand children and young people as social actors in their own right; this also involves exploring their voices concerning food and eating (Christensen and James 2000, Metcalfe et al 2008, Pike 2008). As they become teenagers, many parents may be willing to renegotiate the rules and boundaries set for their children (Backett-Milburn and Harden 2004). Nevertheless, at home, particularly in the areas of 
family food practices, teenagers may only be able to contest or define their autonomy within the constraints of their parents' behaviours and wishes. Consequently, their everyday domestic and dietary worlds can only be fully made sense of by examining their social lives more generally, for example through also exploring the practices and beliefs of family, siblings and friends.(Eldridge and Murcott 2000, Eckert, 2004).

Existing literature indicates that socio-economic status remains an important factor underpinning food provision in families. For instance, family income often influences diet (Dowler and Calvert, 1995, Grieshaber, 1997), with socio-economically disadvantaged families tending to eat less 'healthily' than middle class families ( Shaw et al 2000, Sproston and Primatesta 2003) However, the meanings attached to mundane practices of food preparation and eating at home are also intimately connected with family 'habitus', the unconscious logic of practice and rules of acceptable consumption which underpin everyday routines and behaviours (Warin et al 2008). From this perspective, the most taken-for-granted aspects of preparing, eating and choosing food on a daily basis are based on accumulated habits and preferences built up within distinct social groups (Bourdieu 1984). In these ways, whether for the working class or middle class (Tomanovic, 2004), shared past and present knowledge and experience of the social world continue to shape individuals' (and families') identities and understandings of what is appropriate and possible for 'people like me' (Reay 2004). Our two linked studies therefore aimed to tease out some of the ways in which class matters at home. 


\section{Description of studies and methods}

Although designed and funded independently of each other, taken together these two studies were intended to explore the ways in which class might underpin perceptions and practices regarding teenagers' diet, health and weight. Study two $(\mathrm{m} / \mathrm{c})$ was designed to facilitate a critical examination of some of the key findings emerging from study one (w/c). The linked studies therefore explored many similar themes and the topic guides

were broadly comparable. Through interviews with teenagers and the parents/carers who were the main food providers, the two studies also aimed to revisit the relevance of theories about class-based predispositions and distinctions for everyday dietary practices in families.

In both studies an iterative qualitative approach was taken, allowing the exploration of themes emerging during data collection in addition to those formulated at the outset (Britten et al1995). In each study 36 young people aged 13-15 years were interviewed, as were 34 working class and 35 middle class parents/main food providers. The samples comprised equal numbers of boys and girls.

Following ethical approval from relevant education authorities, we gained access to several schools in first, relatively disadvantaged, and second, more advantaged areas in Eastern Scotland. Schools were selected in part on the basis of the numbers of students 
eligible for free school meals (a proxy indicator in the UK for socio-economic status).

For each study we made complex assessments of socio-economic status. A screening questionnaire was administered to collect young people's socio-demographic information (parent/s' occupation; home postcode; family affluence household composition) and details of their physical activity and favourite or regularly consumed foods. For each study we also selected teenagers on the basis of at least one parent's occupation according to NS-SEC (Office of National Statistics, 2005). Family affluence was ascertained from responses to 2 items adapted from the Family Affluence Scale (Currie, Elton, Todd \& Platt, 1997) - whether the teenager had their own bedroom and if the family had at least one holiday in the past year. Deprivation was assessed using the 2001 Carstairs scores for Scottish postcode sectors (McClone, 2004) and the Scottish Index of Deprivation $^{1}$. The families interviewed were predominantly White/Scottish, reflecting the ethnicity of the local population. Double consent was sought for the teenagers: parents were asked to 'opt out' if they did not wish their child to participate; young people and parents each gave their own written consent to be interviewed.

For each study, interviews were conducted firstly with the teenagers, later with the parents who were identified by the teenagers as their main food provider (these were predominantly mothers, though several grandparents were interviewed as the guardian/main food provider in study one (w/c)). Qualitative interviews, lasting about one hour, took place in teenagers' homes and were tape recorded with their consent. The topic guide was similar for both studies and, each time, the parents' guides mirrored those

\footnotetext{
${ }^{1}$ http://www.scotland.gov.uk/News/Releases/2006/10/17104536).
} 
used previously with the young people. We asked all interviewees to talk through typical and non-typical days enabling us to probe, in some detail, about all food consumed by the participating teenager and his/her family and the context for this consumption (where, with whom and when consumption took place). In this way food and eating were explored in the context of descriptions of the everyday lives of parents and teenagers at home, school, work and leisure.

Tapes were transcribed verbatim and anonymised. Throughout the analysis, selected transcripts were read by each team member, along with the research fellow's field notes and interview summaries. Emerging themes were noted independently. Regular analytical team meetings were held to discuss recurrent themes and any accounts that did not fit with the emerging thematic framework (Boyatzis 1998). The analysis proceeded until the team felt that each broad theme had been fully considered and defined, with continuous reference to the original transcripts. Some of the insights gained in study two $(\mathrm{m} / \mathrm{c})$ developed iteratively through comparisons with study one (w/c). Analysis focused on each broad theme that had emerged, with each team member independently considering finer, sub-themes. These were discussed as a team until consensus was reached. QSR NUD*IST was used for data coding and retrieval. Any names used throughout the paper are pseudonyms.

\section{Findings}

\section{Parental perspectives on managing young teenagers'food practices at home}


We begin with the parents' perspectives to show some of the background framing the teenagers' accounts. In both studies, teenagers reported instances of parental control of their food choices at home through rules, expectations or 'standards' of food and eating practices. Although young peoples' accounts suggested they could also negotiate some flexibility around meal time patterns, few interviewees in either study reported trying to bend parental food rules or change parental food provisioning practices to any great degree. The working class and middle class parents' perspectives on managing young teenagers' food practices at home accounts were, however, somewhat different. It is important that these are understood as embedded in the broader habitus and socioeconomic circumstances/ environments in which these families lived. Working class and middle class parents' perspectives will now be discussed in turn and comparisons returned to in the conclusions

One major difference between the two studies was in the amount of control parents seemed to feel they should, or indeed could, exercise over teenagers' food consumption at home. In study one (w/c) the working class interviewees appeared largely to accept that, within the economic constraints affecting the kinds of foods provided at home, their young teenagers could make their own dietary choices. It was also evident in the working class study that, even though commensality might be valued, many of these teenagers were able regularly to eat elsewhere in the house, or on their own, for example in their rooms or in front of the television. Reflecting findings from other studies, it appeared to be the exception rather than the rule for times, places and contents of meals or snacks to 
coincide for the working class teenagers and their parents on any kind of regular basis (Eldridge and Murcott 2000). For instance, in about half of the working class families it was reported that teenagers always, or nearly always, ate at the same time, and in the same room, as the rest of their family (not all of this sample owned or used a table which could accommodate all family members); in the middle class sample almost all of the families reported commensality round a table to be the norm in their homes.

In study one (w/c), many parents spoke about their young teenagers' food choices and eating practices as being increasingly their own responsibility. Many of these parents said things such as 'at his age he'll eat what he wants to eat'(Alec's mother) and 'I just leave him up to hisself' (Neil's mother). One mother spoke about her difficulties in exercising control over her daughter's eating as follows:

'I think for me, it's important for her going to school with even a bowl of cereal or a piece of fruit or something like that. But her appearance is more important and she'll maybe grab a packet of crisps going up the road, which is not, in my view it's not, it's no good enough, but what can I do? I mean I cannae (cannot) force food down her neck'. (Leanne's mother). (Backett-Milburn et al, 2006)

The working class parents seemed also to feel that their teenagers had strong food preferences and tastes, which should be accommodated; they described in detail what each of their children liked and disliked to eat. They seldom seemed to insist that teenagers should eat anything they disliked even if, as was particularly the case with 
vegetables and sometimes fruit, the majority of our working class parents also clearly stated that they saw these as being 'good for them'. Despite the fact that almost all of these parents said that healthy eating was important, most tended not to question their teenager's distaste for many 'healthier' foodstuffs, though they did say that they tried to counteract this with some of the food provided at home. Having relatively limited food budgets also seemed to affect parents' behaviour; it seemed important to them that food was not wasted and was also fairly shared within the family. In this regard, for instance, some parents who described their offspring as 'good eaters' said this not because the teenager ate 'healthy' foods but because s/he did not complain about or ate all of the food provided at home. Parents did however complain about the teenager if s/he took more than his/her allocated share, or another family member's share, of the foods they had bought for the home (Backett-Milburn et al 2006).

These findings must be located in an appreciation of what is happening in many homes in the $21^{\text {st }}$ Century and the wider challenges facing families. Importantly, study one (w/c) also showed that their teenagers' eating behaviours were not the most pressing concerns expressed by this predominantly low income sample. Food choices and eating practices seemed to be given a fairly low priority in the 'hierarchy of worries' (Backett-Milburn et al 2006) about 'risky' early teenage health-relevant and social behaviours. However, it was not that dietary matters were unimportant to these working class parents, they were simply viewed as less important than other worries about children at this particular age. Echoing other studies (Seaman et al 2006), many of these less advantaged parents described the challenges and risks, such as poor school performance and opportunities, 
drugs, 'getting in with a bad crowd', facing their offspring in their local environments both now and in the future. Such worries about teenagers and their futures may be exacerbated when parents are living in disadvantaged circumstances, have fewer resources at their disposal, and are raising their children in potentially less safe environments (Backett-Milburn et al 2006).

Moving on now to study two (m/c) (Backett-Milburn et al 2008), like their more disadvantaged counterparts, the middle class parents spoke of wanting to provide good food at home and saw 'junk foods' as temptations for all teenagers. However, their interviews in study two $(\mathrm{m} / \mathrm{c})$ revealed a somewhat different environment and habitus in which they strove to achieve these aims. Importantly, most middle class parents' accounts appeared rooted in a taken-for-grantedness that family members enjoyed good health (many did not in the more disadvantaged families). They described living in relatively secure and unthreatening environments regarding health and resources, and their children's experiences with school, friends and peers were largely experienced as positive. All family members, but there was a particularly strong focus on the children, were portrayed as able to lead active lives and afford to participate, for example, in organised sports, dance, gyms, music etc, which were accorded strong social value. Although often admitting to falling short of their ideals, many middle class parents in this second study also spoke about trying to set a good example to their children with regard to health, eating well and leading what they described as full and active lives. By contrast, many of the working class parents seemed less secure about the example they might be setting in this regard. 
These middle class parents' interviews showed they were also assuming continuing success and happiness for their children and, in this, they might be characterized as having future oriented 'hierarchies of luxury and choice'. Controlling and moulding teenagers' food practices, tastes and manners, particularly at home, were accorded high priority as the future social adult would need to accommodate various environments, including eating environments (Backett-Milburn et al 2008). Eating together as a family was one of the food practice ideals expressed by these middle class families. However, it appeared that, in practice, the number of children's after school activities often meant this was only achieved for some family members on any particular evening (though sitting together at table was still maintained). The parents also said that, on the whole, home cooked (or at least home-prepared) meals were provided most evenings; they aimed to cook from scratch as much as possible, and special efforts were made at weekends to offer more elaborate meals, such as roast dinners. The majority of middle class parents also described controlling portion sizes by serving food onto the plates for their families and/or telling their teenager if they felt they were eating too much or not taking enough vegetables. It seemed, from most middle class parents' interviews, that they thought their teenager was eating enough fruit and vegetables, even if they had to hide these in soups or stews, or the teenagers did not always enjoy them (Judith's mother:'we eat-lots of vegetables, much to their horror'). These claims were borne out in the teenagers' own interviews. 
However, as in the working class study, the free exercise of food choices and tastes in their children was felt by the middle class parents to become more of a challenge as they became teenagers. As Catriona's mother explained:

I think you've got a role as a parent to guide them in what you think they should eat and to be honest with them but there's only... but teenagers have got independent minds and I think there's only so far you can go. (Backett-Milburn et al 2008)

Although controlling teenagers' eating practices was presented as an ongoing challenge by middle class parents, active supervision and surveillance of their diets was described, as was guiding tastes in 'the right direction'. This sense of overall parental control also permeated accounts of the other eating opportunities at home in the middle class study. In contrast to study one $(\mathrm{w} / \mathrm{c})$, the majority of middle class parents claimed either that the teenagers rarely took snacks without parental consent, stating that they had 'trained them well' (Nathan's mother), or that the teenager had sufficient self discipline to limit his/her own consumption of snack (or junk) foods. If they discovered their teenager was buying additional sweets or snacks, most of the middle class parents described challenging or reprimanding them. Others said they severely limited having biscuits or snacks in the house (Judith's mother: 'I tend, rather than put temptation in her way, I tend just not to do it, so none of us have it'). Controlling and moulding teenagers' eating practices at home, particularly if they were not as healthy as these middle class parents wished, was often described like a family project (Backett-Milburn et al 2008). 
Already, then, we can see that there were some differences between the environments in which our two sets of teenagers lived and the ways in which their parents spoke about looking after everyday eating practices at home. Both sets of parents identified the increasing autonomy of teenagers as a threat to healthy eating practices, as was the ready availability and attractiveness of 'junk' foods. Both sets of parents said that they tried to provide a good diet at home, though exactly what this comprised varied and the middle class interviews suggested a greater belief in their ability to control and mould teenagers' tastes and choices than did those of the working class. However, parents' views are not stand alone entities. Although our studies showed that parents were in overall charge of food provisioning and eating practices at home, health-relevant behaviour is interactive and teenagers are also creating meanings and practices for themselves (Wills et al 2008). Against this backdrop of parental accounts we now examine what the teenagers themselves said about their food and family practices at home and how they spoke about the negotiations surrounding these processes between themselves and their parents.

\section{Teenagers' accounts of negotiating food and family practices at home}

Food provision in the family home: teenager perspectives on tastes, preferences and parental control

In study one (w/c) the working class teenagers offered a somewhat different view about the extent to which they could choose what they ate at home than did their parents, most of whom seemed to feel that it was up to the teenager to decide. Parents, especially 
mothers, were reported by the working class teenagers as having a great deal of control over what was available for them to eat at home. Almost all of the working class teenagers said they were not usually asked what they wanted to eat and the main food provider was rarely described as consulting with other family members about meals that were prepared. Many, however, described having some autonomy over what they actually chose to eat and where they could eat this. Only a minority of the working class teenagers said that they had to ask their parents before taking or preparing any food or drink at home. Jodie was unusual in saying, for example: 'my mum disnae trust me. Even when I make a cup o' tea, it's like 'watch that water!'.

The working class teenagers reported sometimes being asked if there were particular foods they would like bought in the family shopping; those who were not asked said they often requested particular foods, or brands of foods. They did not, however, always receive the foods they asked for and this, they explained, was related to the price being prohibitive or a parent forgetting. Parents and grandparents were also described as exerting some control when young people came home from school for their lunch. In these situations, according to the teenagers, parents/grandparents usually provided the food on a daily basis without asking young people what they wanted. Overall, however, the working class teenagers' interviews indicated that, where they identified opportunities for choice around food and eating practices at home, they regularly seemed to negotiate with parents or simply got their own way. Compared with the middle class teenagers this appeared to resulting in a much greater amount of freedom about what they themselves could choose to eat. 
In addition, about half the working class teenagers reported that they ate differently from their families by sometimes or often preparing food for themselves. These teenagers said they made themselves something to eat so they could more easily organize their social lives, without relying on parents and parent's own timetables. The foods prepared by these teenagers were, typically, sandwiches, instant-noodles and food that could be heated up (e.g. tinned food) (Wills et al 2008). Such independence in domestic food preparation was seldom reported by the middle class teenagers.

Almost all of the working class teenagers also reported that parents had rules or expectations about the kinds and amounts of food they might eat in the home. These included: particular foods being restricted (usually fizzy drinks, sweets, crisps and biscuits but sometimes milk, yogurt or fruit juice); having to ask before taking a snack or drink (although fruit was said to be readily available); and not being allowed to eat a snack when a main meal was about to be served. Lorna was one of several working class teenagers who described trying to override her mother's rules, as the quotation below illustrates.

Interviewer: So does she ever know that you have taken more than one [bar of chocolate]?

Lorna: Mmh, she usually searches me. When I walked away, like this morning she searched my school bag 'cause I was in the cupboard and I shut my bag really fast 'cause I have a big bottle of juice... of course she opened my bag to 
see how many sweets and that I had taken (laughter).

In these socio-economically disadvantaged families many working class teenagers appeared to accept that some food rules were necessary to ensure that no one in the family ate more than their 'fair share' of food (often so that food lasted until the next shopping trip) About a quarter of teenagers in study one (w/c) reported that certain foods were not to be eaten because they had been bought for other family members (for example, full sugar drinks for parents; 'diet' yogurts for an older sister) (Wills et al 2008).

Nevertheless, echoing their parents' accounts, the young teenagers in our working class study clearly expressed their likes and dislikes regarding food and described how they managed to negotiate the foods they preferred and avoid those they disliked. Many of them commented that their food preferences were dissimilar to parents or siblings and spoke of how they managed to avoid eating the foods that other family members liked (particularly vegetables). Nicole, for example, rarely ate her evening meal with her mother, partly because of their different schedules, but also because she did not like the food her mother ate:

Interviewer: Do you have [your meal] on your own or with your Mum or ...?

Nicole: On my own, 'cause she's never in, and all she ever eats is tatties (potatoes) and I canny (cannot) bear tatties every day Interviewer: What, just tatties on their own? 
Nicole: Tatties, turnip and cabbage, I've had it a couple of times but I like pasta.

Being aware of their own food preferences and tastes seemed to lead many of the working class teenagers to label themselves as fussy or greedy eaters. Only a minority reported that their tastes had changed as they got older, which meant they were now prepared to try a greater range of foods. Fruit and vegetables were frequently described as the subject of particular argument between parents and young teenagers. Even though most parents and teenagers reported that they were encouraged to eat vegetables and salad, very few working class teenagers said they were willing to eat these. For example, Neil said peas were the only vegetable he liked, but then went on to explain:

Neil: 'If the food looks dodgy, I dinnae eat it... [Mum] tries to make me sometimes, if she's haeing [having] green beans or that. She'll put a couple on my plate' Interviewer: 'Do you eat them?' Neil: 'Nah'

(Wills et al 2008)

From their interviews, the middle class teenagers appeared to have very limited autonomy and choice in relation to family meals. Parents' control and shaping of young people's food choices and consumption can be seen particularly in decisions regarding meal preparation. The majority of parents preparing meals were described as deciding on 
the food without consulting young people or other family members, although young people said they could make occasional requests. Compared to the way that parents catered for their individual tastes, as reported by teenagers in study one (w/c), most of the middle class teenagers said they shared similar tastes to the rest of their family. Overall they only commented on one or two things that they did not like in relation to the other family members and some commented that meals would be a compromise, incorporating the food liked by all family members. In a few families members would eat the same general meal but within that there were some limited adaptations to accommodate tastes, for example providing a different protein dish for a vegetarian alongside shared vegetables and carbohydrates. In general, however, these middle class teenagers seemed to accept that families should eat the same meals together and also that family members would fit in with each others' tastes and preferences to make that possible.

Moreover, although middle class teenagers said it was often parents who made decisions about both the kinds of food and portions sizes they ate, the majority also reported that they were expected to finish most of their meals, even foods they disliked. It was only the occasional interviewee who said s/he might be allowed not to eat something s/he really disliked. Those who wanted to leave food that they disliked usually described having to reach some sort of agreement with their parents. For example, one boy mentioned making a deal with his parents to finish one food item in order not to eat another. For all, vegetables tended to be non-negotiable. Again, like their parents and unlike most of the working class sample, middle class teenagers appeared to accept that they should eat a 
greater variety of foods and become less fussy as they got older, as the following quotation illustrates:

Callum: It probably wasn't as bad if I left things when I was younger because em, just kind of when you're younger it's, I'd say it's probably expected that you wouldn't like many things but I would still probably be expected to eat most of the stuff that I didn't like. (Backett-Milburn et al 2008) Many of the middle class teenagers did report some autonomy in the area of choosing and helping themselves to snacks at home. However, again, their interviews revealed that this was against the backdrop of clearly defined parental expectations, which, by and large, they adhered to. Many seemed to view such rules or expectations as allowing them to control their own consumption both in quantity and choice. Most of the middle class teenagers said they were allowed to help themselves to fruit and drinks but had to ask permission for snacks like crisps, biscuits and chocolate; other items, such as fizzy juice, were described as special treats. For some, choice of snacks was not a real option as only 'healthy' options were available. For example, Fiona said she did not have to ask permission for snacks because they were all sensible snacks and Anna said she was allowed to help herself to snacks because she was both responsible in her choices and not going to 'gorge' herself. However, it appeared that this autonomy was indeed still being monitored as a few middle class teenagers reported that their parents intervened if they did over-indulge in snacking, for example: 
Gareth: No. I mean if, if I am getting like over the top like, I will have eaten like 4 bananas or something in a night they'll say you know, "stop". Or if I've, you know I've been drinking too much fizzy juice or something like that, they'll just say "stop".

Shona: Like say I took um... a Kit-Kat or something, she (mother) would find out the next day and we'd sit down for about ten minutes and she'd be sitting questioning us, asking me like "did I take it?”, "why did I take it?" "why didn’t I ask?”.

The middle class teenagers' accounts of eating at home revealed a considerable degree of parental regulation. However, sitting at the table sharing a family meal was not described as a curtailment of freedom by them, but rather as a social event, an opportunity to chat to other family members. Families who did not eat together were seen as not engaging in 'family time'. Middle class teenagers' reports that parents made only limited accommodation for tastes and preferences did not necessarily seem to be viewed in a negative light as many said that they had similar tastes to the rest of the family or that they liked the food that was provided. They described being encouraged to try new foods and to eat what they had been served. Here, though, their discussions about leaving food behind appeared to be less about food wastage and more about having a varied diet, eating foods because these were 'healthy' and developing more sophisticated tastes.

\section{Conclusion}


These two linked studies have raised some interesting similarities and contrasts between young teenagers' experiences of domestic food and eating practices in differing socio economic groupings. Interestingly, both sets of teenagers described how they felt they were provided with foods at home over which they had relatively little control, these were largely choices made by their parents, predominantly their mothers. Few teenagers in either study reported trying to bend parental food rules or change parental food provisioning practices to any great degree. However, the middle class interviewees portrayed themselves as generally approving of the family food provided and prepared by parents at home whereas many of the working class teenagers regularly chose to prepare food for themselves, particularly when this facilitated their social lives or not having to eat the same foods as their parents. In some ways, therefore, the working class teenagers seemed to have greater autonomy over what and where they actually ate

Parents in both studies spoke of the teenage years as heralding potential changes in their children's food choices and eating practices, most notably that teenagers would have a taste for and more opportunities to eat junk food (Wills et al in press) .

However, with regard to what happened at home, the working class and middle class parents appeared to react to this in different ways. By and large, the middle class teenager was expected to strictly limit his/her snack or junk food intake and this was monitored by the parents. In comparison, most of the working class parents, although not unconcerned, nevertheless felt there was little they could do to control these teenager tastes. 
Our qualitative interviews, however, enabled us to understand these apparent classbased differences within the habitus, or cultures, of these families. Teenagers' domestic food practices need also to be seen in the light of wider socio- economic circumstances and perceived opportunities. It seemed that the working class parents, although expressing wishes for a healthy diet, placed such issues fairly well down their 'hierarchies of worries' about their teenagers' presents and futures. Other concerns about their teenagers' lives were simply more pressing for them. In contrast, against the backdrop of relatively secure and healthy environments and reasonably assured future prospects for their teenagers, middle class parents were better able to focus on moulding their eating practices and tastes. Against this backdrop of 'hierarchies of luxury and choice' a focus on their teenagers' appropriate food and eating practices also appeared to be part of the process of making the future middle class adult. 


\section{References}

Backett-Milburn, K., Wills, W. J., Gregory, S., and Lawton, J., 2006. Making sense of eating, weight and risk in the early teenage years: views and concerns of parents in poorer socio-economic circumstances. Social science and medicine, 63 (3), 624-635.

Backett-Milburn, K; Wills, W; Roberts, ML; Lawton, J.2008 Food, eating and weight: parents' perspectives on the making of the middle class teenager. Draft paper (currently under journal consideration) attached to final report to the ESRC, Parents' \& teenagers' conceptions of diet, weight \& health: Does class matter? Res 000231504.

Swindon:ESRC. 
Backett-Milburn, K. and Harden, J., 2004. How children and their families construct and negotiate risk, safety and danger. Childhood, 11(4), 429-447.

Ball, K. and Crawford, D., 2005. Socioeconomic status and weight change in adults: a review. Social science and medicine, 60(9), 1987-2010.

Bradley, H., 1996. Fractured identities: changing patterns of inequality. Cambridge: Polity Press.

Bourdieu, P., 1984. Distinction: a social critique of the judgement of taste._London: Routledge and Kegan Paul.

Boyatzis, R. E. (1998). Transforming qualitative information: thematic analysis and code development. . Thousand Oaks, CA, Sage.

Britten, N. Jones, R. Murphy, E. and Stacy, R., 1995. Qualitative research methods in general practice. Family practice, 12(1), 104-114.

Caplan, P., 1997. Approaches to the study of food, health and identity. In P. Caplan, ed. Food, health and identity. London: Routledge. 
Christensen, P. and James, A., Eds. 2000. Research with children: perspectives and practices. London: Falmer Press.

Colls, R. and Evans, B. 2008. Embodying responsibility: children's health and supermarket initiatives. Environment and Planning A, 40(3) $615-631$.

Crossley, N., 2004. Fat is a sociological issue: obesity rates in late modern 'body conscious' societies. Social theory and health, 2, 222-53.

Devine, C. Jastran, M.,Jabs, J.Wethington, E. Farell, T.J. and Bisogni, C. A., 2006. “A lot of sacrifices:" Work-family spillover and the food choice coping strategies of lowwage employed parents. Social science and medicine, 63, 2591-2603.

Dietz, W., 2001. The obesity epidemic in young children. British medical journal, 322, $313-314$.

Dixey, R. Sahota, P. Atwal, S. and Turner, A., 2001. 'Ha ha, you're fat, we're strong”; a qualitative study of boys' and girls' perceptions of fatness, thinness, social pressures and health using focus groups. Health education, 101(5), 206-216.

D'Houtard, A. and Field, M., 1984. Images of health: variations in perceptions by social class in a French population. Sociology of health and illness , 6: 30-60. 
Dowler, E. and Calvert, C., 1995. Looking for 'fresh' food: diet and lone parents Proceedings of the nutrition society 54: 759-769.

Dowling, R., 2009. Geographies of identity: landscapes of class. Progress in Human Geography 33: 833-839.

Eckert, G., 2004. 'If I tell them then I can': ways of relating to adult rules. Childhood, 11(1): 9-26.

Egger, G. and Swinburn, B., 1997. An 'ecological' approach to the obesity pandemic. British medical journal, 315, 477-80.

Eldridge, J. and Murcott, A., 2000. Adolescents' dietary habits and attitudes: unpacking the 'problem' of (parental) influence. Health, 4(1), 25-49.

Grieshaber, S., 1997. Mealtime rituals: power and resistance in the construction of mealtime rules. British journal of sociology 48(4): 649-666.

Henderson, L. Gregory, J.and Swann, G., 2002. The national diet and nutrition survey: adults aged 19-64 years. London: The Stationery Office. 
Kaufman, L., and Karpati, A. 2007. Understanding the sociocultural roots of childhood obesity: food practices among Latino families of Bushwick, Brooklyn. Social science and medicine, 64, 2177-2188.

Lupton, D., 1994. Food, memory and meaning: the symbolic and social nature of food events. The sociological review, 42(4).

Metcalfe, A., Owen, J., Shipton, G., and Dryden, C. 2008. Inside and outside the school lunchbox: themes and reflections. Children's geographies, 6, 4, 403-412.

Morgan, D., 1996. Family connections. Cambridge: Polity.

Pike, J., 2008. Foucault, space and primary school dining rooms. Children's geographies, 6 (4), 413 - 422.

Reay, D., 2005. Beyond consciousness? The psychic landscape of social class. Sociology, 39(5), 911-928.

Sarlio-Lahteenkorva, S., 2007. Determinants of long-term weight maintenance. Acta paediatrica, 96, 26-28.

Seaman, P., Turner, K., Hill, M., Walker, M., and Stafford, A., 2006. Parenting and children's resilience in disadvantaged communities. London: National Children's Bureau. 
Shaw, A. McMunn, A. and Field, J., 2000. The Scottish health survey 1998. London: Joint Health Surveys Unit.

Sproston, K. and Primatesta, P.,2003. Health survey for England 2003: risk factors for cardiovascular disease. London: The Stationery Office.

Tomanovic, S., 2004. Family habitus as the cultural context for childhood. Childhood, 11, 339-360.

Valentine, G., 1999. Eating in: home, consumption and identity. The sociological review, 47(3): 491-524.

Warde, A. and Hetherington, K., 1994. English households and routine food practices: a research note. The sociological review, 758-778.

Warin, M. Turner, K. Moore, V. and Davies, M., 2008. Bodies, mothers and identities: rethinking obesity and the BMI. Sociology of health and illness, 30(1), 97-111.

West P., and Sweeting, H., 2004. Evidence on equalisation in health in youth from the West of Scotland. Social science and medicine, 59:13-27. 
Wills, W. J., Backett-Milburn, K., Gregory, S. and Lawton, J., 2008. 'If the food looks dodgy I dinnae eat it': Teenagers' accounts of food and eating practices in socio-

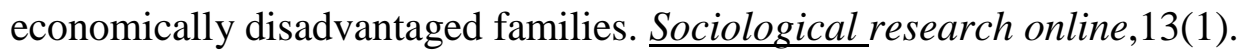

Wills, W.J., Backett-Milburn, K., Lawton, J. and Roberts, E.M. (in press) Consuming fast food: the perceptions and practices of middle class young teenagers in Children, food and identity in everyday life. James, A., Tingstad, V. and A. Kjørholt (eds). London, Palgrave.

Williams, S., 1995 Theorising class, health and lifestyles: can Bourdieau help us? Sociology of health and illness, 17(5), 577-604.

Wright-St Clair, V. Hocking, C. Bunrayong, W. Vittayakorn, S. and Rattakorn, P., 2005. Older New Zealand women doing the work of Christmas: a recipe for identity formation. The sociological review: 332-350.

Word count 7300 